\title{
ECONOMIC EVALUATION MODEL FOR POST-EARTHQUAKE REPAIR/REHABILITATION OF BRIDGE
}

\author{
Min-Yuan Cheng and Yu-Wei Wu \\ Department of Construction Engineering, \\ National Taiwan University of Science And Technology \\ \#43,Sec.4,Keelung Rd.,Taipei,106,Taiwan,R.O.C \\ $\{$ myc, D9305503\}@mail.ntust.edu.tw
}

\begin{abstract}
Taiwan's location in a zone of strong seismic activity means that earthquakes regularly threaten human life and transportation facilities. The importance of bridges in Taiwan's transportation grid makes the destruction or damage of such during earthquakes impact significantly on people's livelihood. However, within the grid, the importances of individual bridges differ from one another in terms of their importance/impact on society. Therefore, a key element in reducing overall economic costs is determining in a quick and efficient manner which bridges deserve priority consideration for immediate repair/rehabilitation following a destructive natural incident. Thus, this research establishes an economic evaluation model for post-earthquake bridge repair/rehabilitation to enhance the effectiveness and efficiency of decision making. Engineering and additional travel costs are then assessed to evaluate the lowest cost and shortest time within all repair/rehabilitation schemes in order to identify and define the optimal emergency plan.
\end{abstract}

\section{KEYWORDS}

Bridge, Earthquake, Repair, Rehabilitation, Economic Evaluation

\section{INTRODUCTION}

Taiwan, in a zone of significant seismic activity, is notable for its mountainous terrain and numerous river systems. Road system construction requires the regular use of bridges to span natural barriers. Bridges, therefore, represent a vital link in Taiwan's transportation grid, necessary to move both the daily necessities of life and the imports and exports that remain the lifeblood of Taiwan's economy. Damage to bridges in a severe earthquake will inevitably impact communications, delay or cut the transit of urgent aid and materials, and seriously impede the decision making process. Appropriate bridge repair/rehabilitation activities should be carried out as soon as possible to maintain a minimum level of performance [1]. While there has been a considerable increase recently in research on the repair and rehabilitation of damaged bridges [2], authors have not effectively considered in their research the issue of economic needs and benefits $[3,4,5]$. Consider the problem posed by a damaged bridge that links two areas with low population densities. Bridge managers face high premiums in maintaining bridge services that demand high costs and provide low benefits. Deciding which bridges deserve immediate repair / rehabilitation and what level of repair / rehabilitation is justified by current budget constraints represent a complex dilemma for bridge managers. An effective bridge repair strategy, therefore, is an optimization problem that must combine a selection of bridges in most need of repair / rehabilitation with different repair / rehabilitation levels in order to maximize the total benefit delivered.

Based on the above, this research offers an analysis model to promote the effectiveness and efficiency of repair/rehabilitation decision making in order to develop feasible repair/rehabilitation schemes using an emergency repair estimation 
model, and then constructs a travel cost estimation model, using ArcGIS to find the shortest path and TransCAD to analyze traffic assignments. Engineering and additional travel costs are then assessed in the Economic Evaluation Model to evaluate the lowest cost and shortest time within all repair/rehabilitation schemes in order to identify and define the optimal emergency plan.

\section{CATEGORIZATION OF POST-EARTHQUAKE BRIDGE REPAIR/REHABILITATION TECHNIQUES}

This research focuses on the reinforced concrete (RC) bridges, various bridge elements were selected according to bridge structures. The categorization of bridge structures and elements is presented in Figure 1. The bridge structures and elements code is shown in Table 1. Different researchers have suggested different maintenance activity classifications and definitions. This research subdivides maintenance into post-earthquake repair and rehabilitation as defined by Harper [6] and Liu et al. [7] and described as follows (see Figure 2.):

(1) Repair activities are those that restore normal surface conditions and extend the useable life of bridges (e.g., patching and sealing).

(2) Rehabilitation activities are those that restore damaged structures to "original" condition (e.g., attaching additional girders or plates).

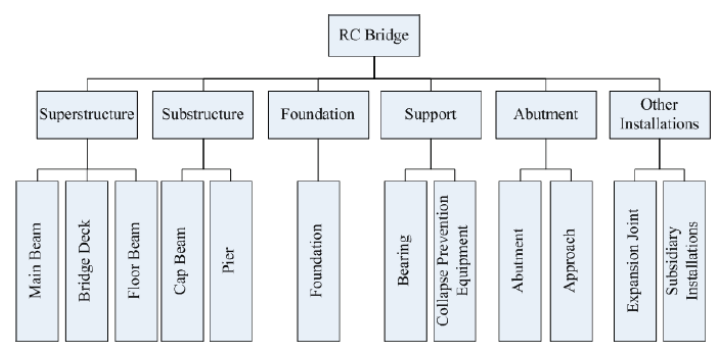

Figure 1 Categorization of Bridge Structures and Elements

\section{ESTABLISHING POST-EARTHQUAKE DISASTER EMERGENCY RESPONSE MECHANISMS}

The national-level Disaster Prevention and Rescue Committee classifies disaster prevention and rescue measures into three distinct categories. These include disaster prevention, disaster contingency response and disaster restoration and rehabilitation. This research, which established a bridge earthquake disaster response procedure in accordance with the "Basic Plan of Disaster Prevention and Rescue in Taiwan", addresses needs in three categories as follows: "disaster emergency response", "emergency restoration" and "planned rehabilitation and reconstruction".

Table 1 Bridge structures and elements code

\begin{tabular}{|c|c|c|c|}
\hline $\begin{array}{c}\text { Bridge } \\
\text { Structure }\end{array}$ & $\begin{array}{c}\text { Structure } \\
\text { Code }\end{array}$ & Bridge Element & $\begin{array}{c}\text { Element } \\
\text { Code }\end{array}$ \\
\hline Superstructure & Sup. & $\begin{array}{c}\text { Main Beam; } \\
\text { Bridge Deck; } \\
\text { Floor Beam }\end{array}$ & $\begin{array}{c}\text { Sup.1; } \\
\text { Sup.2; } \\
\text { Sup.3 }\end{array}$ \\
\hline Substructure & Sub. & $\begin{array}{c}\text { Cap Beam; } \\
\text { Pier }\end{array}$ & $\begin{array}{c}\text { Sub.1; } \\
\text { Sub.2 }\end{array}$ \\
\hline Foundation & F. & Foundation & F.1 \\
\hline Support & S. & $\begin{array}{c}\text { Bearing; } \\
\text { Collapse-Preventing } \\
\text { Equipment }\end{array}$ & $\begin{array}{c}\text { S.1; } \\
\text { S.2 }\end{array}$ \\
\hline Abutment & A. & $\begin{array}{c}\text { Abutment; } \\
\text { Approach }\end{array}$ & $\begin{array}{c}\text { A.1; } \\
\text { A.2 }\end{array}$ \\
\hline $\begin{array}{c}\text { Other } \\
\text { Installations }\end{array}$ & O & $\begin{array}{c}\text { Expansion Joint; } \\
\text { Subsidiary } \\
\text { Installations }\end{array}$ & $\begin{array}{c}\text { O.1; } \\
\text { O.2 }\end{array}$ \\
\hline
\end{tabular}

Checkpoints used in the investigation questionnaire are simple and clear, and therefore, correspond directly to a bridge's overall damage level, which this research categorized into four levels, as follows:

(1) Level A: Abnormal conditions such as serious tilt, sag, bridge deck / support collapse and damage to subsidiary installations which cause a bridge to become impassable. Moreover, damage continues to occur, with further secondary destruction occurring that further restricts passage. 
(2) Level B: Abnormal conditions such as tilt, sag, displacement, height differentiation, and support damage that negatively impacts upon bridge safety require that restrictions be imposed upon passage type.

(3) Level C: While abnormal conditions are present, normal passage is unaffected.

(4) OK: No abnormal conditions are present and a bridge is safe to pass.

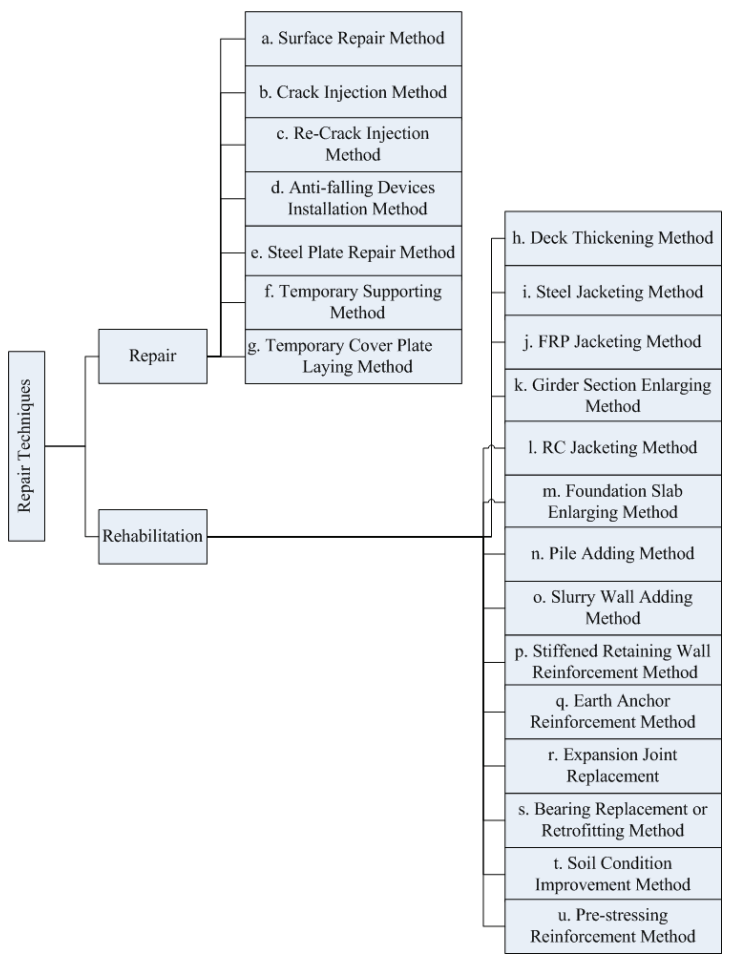

Figure 2 Categorization Framework of Post-Earthquake Bridge Repair Technique

Based on different levels of bridge safety, repair/rehabilitation techniques can then be applied to different emergency procedures.

Finally, research integrates all information to create a relationship between emergency procedures and repair/rehabilitation techniques. This relationship is illustrated in Table 2. Bridge managers can identify suitable repair/rehabilitation activities at different emergency levels by referencing this table.

\section{ESTABLISHING AN ECONOMIC EVALUATION MODEL FOR POST-EARTHQUAKE BRIDGE REPAIR/REHABILITATION}

Determining which bridges that have been destroyed or damaged require immediate repair/rehabilitation and targeting the proper repair/rehabilitation resources to each bridge represent important tasks for bridge managers. The additional travel costs incurred by road users required to take alternate routes is also a factor that bridge managers should consider when selecting repair/rehabilitation plans. In light of the above, the Economic Evaluation Model for Post-Earthquake Bridge Repair/Rehabilitation was developed to assist bridge managers to evaluate relevant feasible strategies. As shown in Figure 3, the Economic Evaluation Model framework consists of three main parts.

Table 2 Suitable Repair/Rehabilitation in Different Level of Emergency Evaluation

\begin{tabular}{|c|c|c|c|}
\hline \multirow{2}{*}{$\begin{array}{l}\overrightarrow{0} \\
\frac{\overrightarrow{0}}{0}\end{array}$} & \multicolumn{3}{|c|}{ Emergency Restoration } \\
\hline & $\begin{array}{l}\text { Level of } \\
\text { Emergency } \\
\text { Evaluation }\end{array}$ & $\begin{array}{c}\text { First Priority } \\
\text { Technique }\end{array}$ & $\begin{array}{l}\text { Further } \\
\text { Technique }\end{array}$ \\
\hline \multirow{3}{*}{$\stackrel{\vec{Z}}{\overparen{O}}$} & A & $\mathrm{abe}$ & - \\
\hline & B & $\mathrm{f}$ & b i \\
\hline & $\mathrm{C}$ & $\mathrm{f}$ & b i \\
\hline
\end{tabular}

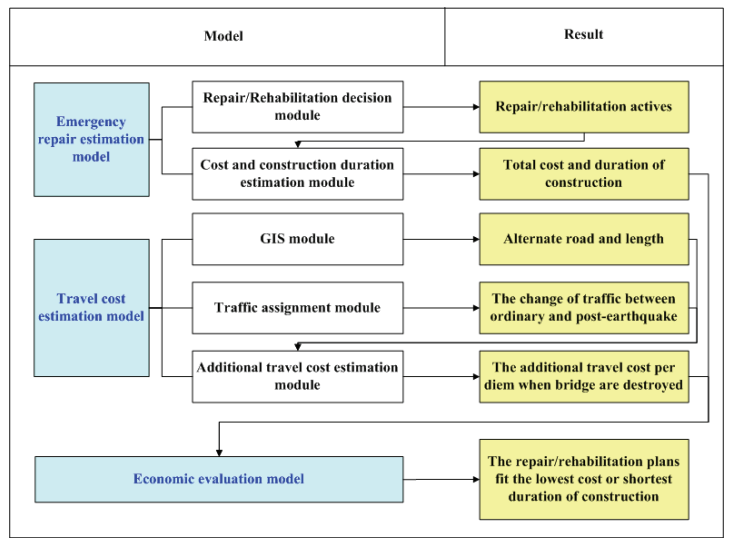

Figure 3 Model Architecture 
(1) Emergency repair estimation model: This model derives feasible repair/rehabilitation schemes using a repair/rehabilitation decision module and derives rough cost and construction duration times using a cost and construction duration estimation module.

(2) Travel cost estimation model: This model identifies the shortest path using a GIS module and analyzes traffic information with a traffic assignment module. Both help estimate the additional travel costs attributable to use of an alternate route.

(3) Economic evaluation model: This model integrates the result from the emergency repair and travel cost estimation models. Engineering and travel costs are considered within all kinds of repair/rehabilitation schemes in order to identify the most appropriate emergency plan and maximize total benefit.

\subsection{Emergency Repair Estimation Model}

\subsubsection{Repair/Rehabilitation decision module}

This research divides emergency repair into first and second priority categories. Preliminary evaluation results suggest that repair/rehabilitation techniques differ for different evaluation levels. Some pictures taken of the aftermath of the Chichi, Taiwan earthquake (September 21, 1999) help users better appreciate the elements relevant in assigning evaluation levels. The evaluation level will guide the application of specific techniques to different structures and bridge components.

\subsubsection{Cost and Construction Duration Estimation Module}

Research integrated all repair/rehabilitation information into a form. Users can follow this module to calculate rough costs and construction duration.

\subsection{Travel Cost Estimation Model}

\subsubsection{GIS module}

This research applies ArcGIS, developed using ESRI, to build a GIS module to identify the most appropriate alternate route through which to reroute normal traffic flows. A route analysis can be employed in alternate route identification in cases where a bridge is rendered impassable to traffic. The length of the alternate route can then be calculated.

\subsubsection{Traffic assignment module}

TransCAD is a geographic information system (GIS) designed specifically for transportation professionals to store, display, manage, and analyze transportation data. TransCAD combines GIS and transportation modeling capabilities on a single integrated platform [8]. This research employs TransCAD to perform traffic assignment tasks. Wardrop introduced the User-Optimized Assignment Principle theory into traffic assignment [8], and this study follows Wardrop in using Origin-Destination (O-D) matrix and User Equilibrium to measure traffic flows between the point of traffic interdiction and the nearest point where normal traffic flows without obstruction. The average daily traffic (ADT) value of every route can be calculated using a TransCAD traffic assignment function.

\subsubsection{Additional travel cost estimation module}

This module reconfigures user cost formulas (Ehlen, Mark A., 1997 [9]) to calculate additional travel costs prior to an earthquake event that disrupts traffic. Maintenance and repair of an existing bridge and the attendant rerouting of traffic can lengthen drivers' commute time and increase vehicle operational costs. Roadway accidents also tend to increase when alternate routes are designated.

Such costs of traffic delays, idle capital, and accidents can be computed using simple formulas based on traffic statistics from Taiwan's Ministry of Transportation and Communications (MOTC). The three types of user costs are typically computed include: 1) Driver delay costs: the personal cost to drivers of delays due to taking alternate routes; 2) Vehicle operating costs: additional costs of vehicle maintenance and depreciation due to taking alternate routes; and 3) Accident costs: costs attributable to vehicle damage and human injury due to taking alternate routes.

Equation (1) can be used to compute user costs attributable to traffic delays due to the enforced use of alternate routes.

Driver delay cost $=\left(\frac{L a}{S a}-\frac{L n}{S n}\right) \times A D T \times w$

Where 
$L a$ : Length of alternate route $(\mathrm{Km})$

$L n$ : Length of affected roadway $(\mathrm{Km})$

$S a$ : Traffic speed on alternate route during bridge work activity $(\mathrm{Km} / \mathrm{hr})$

$S n$ : Normal traffic speed on affected roadway $(\mathrm{Km} / \mathrm{hr})$

$A D T$ : Average daily traffic over alternate route, measured in number of cars per day

$w$ : Hourly time value of drivers. The hourly $\mathrm{w}$ is typically a weighted average of commercial vehicle driver's and personal automobile driver's time.

Vehicle operating costs can be calculated using equation (2).

Vehicle operating costs $=\left(\frac{L a}{S a}-\frac{L n}{S n}\right) \times A D T \times r$

Where

$r$ : Weighted-average vehicle cost, measured in US dollars per day

Accident costs can be calculated using equation (3).

Accident costs $=\Delta L \times A D T \times A n \times C a$

Where

$$
\Delta L: \quad \operatorname{La}-\operatorname{Ln}(\mathrm{KM})
$$

$A n$ : Accident rate per vehicle-kilometer

Ca: Cost per accident

Travel cost is equal to the sum of driver delay, vehicle operating and accident costs.

Travel cost $(\mathrm{TC})=$ Driver delay cost + Vehicle operating costs + Accident costs

\subsection{Economic Evaluation Model}

This model considers bridge repair/rehabilitation costs and duration as well as the additional costs incurred when traffic is redirected through alternate routes. Findings can help bridge manager identify repair plans that maximize benefit. Procedures followed to develop this model are illustrated below:

Step 1: Obtain cost and construction duration estimation module results

Cost and construction duration estimation module results show that cost and duration factors should receive priority consideration, followed by other factors, based on the following equations:

$$
\begin{aligned}
& M C_{i j}=F M C_{i j}+P M C_{i j} \\
& M D_{i j}=F D_{i j}+P D_{i j}
\end{aligned}
$$

Where

$M C_{i j}$ : the j-th cost of Element i technique

$M D_{i j}$ : the j-th duration of Element i technique

$F M C_{i j}$ : the $\mathrm{j}$-th cost of Element i first priority technique

$P M C_{i j}$ : the $\mathrm{j}$-th cost of additional Element $\mathrm{i}$ technique

$F D_{i j}$ : the $\mathrm{j}$-th duration of Element $\mathrm{i}$ first priority technique

$P D_{i j}$ : the $\mathrm{j}$-th duration of additional Element $\mathrm{i}$ technique

Step 2: Obtain travel cost estimation module results

Because the travel cost variable is dependent upon construction duration, the maximum value employed to equation (7) to calculate the additional travel cost (TTC) is as follows:

$T T C_{i}=M D M_{i} \times T C$

Where

$T T C_{i}$ : additional travel cost (US dollars).

$M D M_{i}$ : the i-th maximum duration of $M D_{i j}$ (days).

$T C$ : travel cost (US dollars/day)

Step 3: Calculate total cost

Total cost is equal to the sum of the two costs "additional travel" and "construction".

$R C_{j}=\sum_{i=1}^{n}\left(M C_{i j}\right)+T T C_{i}$

Where

$R C_{j}$ : total cost (including the $\mathrm{j}$-th

repair/rehabilitation cost) (US dollars).

$n$ : number of elements

Step 4: Economic evaluation of repair/rehabilitation plan

Step 4 calculates the minimum cost and duration of the repair/rehabilitation plan. Bridge managers may select which of the following two equations they wish to use.

$R C M=\min \left[R C_{j}\right]$

$M D M=\min \left[M D M_{i}\right]$ 
Where

$R C M$ : minimum cost of repair/rehabilitation plan (US dollars).

MDM: minimum duration of repair/rehabilitation plan (days).

\section{THE ECONOMIC EVALUATION MODEL IN PRACTICE - KEELUNG CITY OVERPASS}

A case study was conducted in Keelung City, Taiwan employing the economic evaluation model developed in this study. An overpass in a downtown district of that city had been severely damaged in an earthquake and bridge managers were faced with a decision on whether and how to proceed with repair/rehabilitation work in a way that would maximize overall benefit.

Engineers, following procedures and mechanism for post-earthquake bridge emergency response, collected relevant earthquake data and set up public notices regarding bridge damage. The emergency questionnaire indicated damage at Level A, necessitating closure of the bridge to traffic. As part of emergency restoration, photos of similar bridge damage taken in Chichi after the September 21, 1999 earthquake and standard typical damaged drawings were provided to help provide engineers with a larger perspective for their evaluation level (see Figure 4)

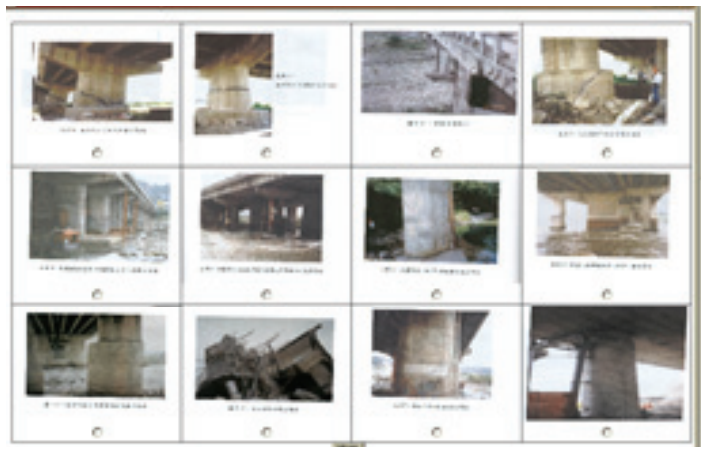

Figure 4 Photos of Historical Damaged Cases

In order to decrease user error, form validations and calculations were performed automatically with JavaScript. Level A was designated due to the presence of crevices in beam. Evaluated construction cost and duration are shown in Figure 5.

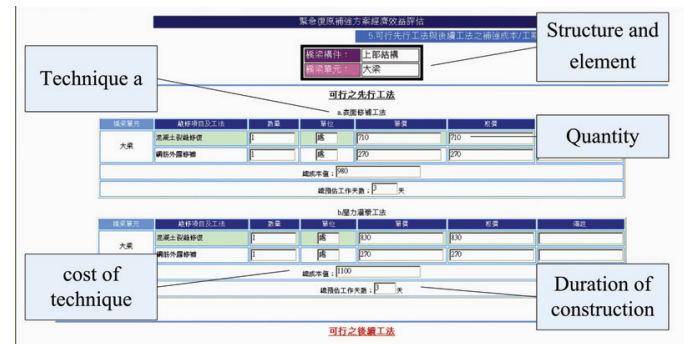

Figure 5 Cost and Duration of Repair/Rehabilitation Evaluation

In the GIS module, the bridge is represented by cross signs and the alternate route and length planned by ArcGIS. Keelung City topography and urban levels were collected and alternate route plans were readied. TransCAD was used to calculate traffic flow in the traffic assignment module. The Keelung City O-D matrix was extrapolated from MOTC data. Traffic assignment equations were bundled in TransCAD.

Total costs, estimated construction duration and additional travel costs were then input into the economic evaluation model. Output results represented the repair/rehabilitation plans that fit respectively the requirements of lowest total cost and shortest construction duration (see Figure 6).

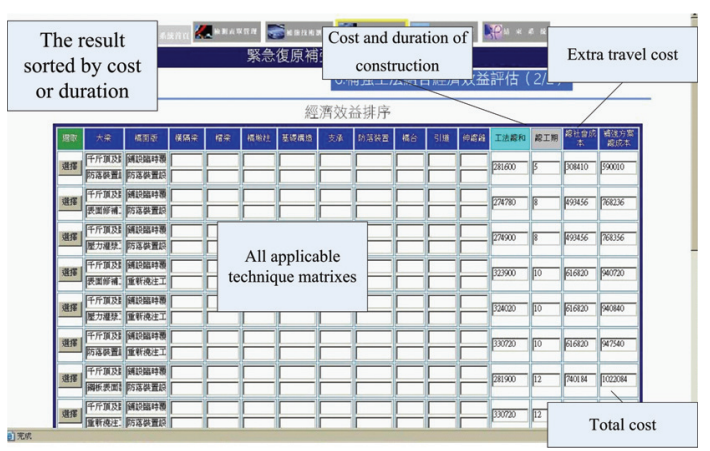

Figure 6 Result of Economic Evaluation Model

\section{CONCLUSIONS}

This research uses data and information from established disaster response procedures and a scientific approach to decide which among many potential emergency measures will most effectively achieve rehabilitation / reconstruction objectives. This research employed traffic assignment to calculate traffic flow changes and integrated user cost formulas to compute additional 
travel costs. The Economic Evaluation model was developed to combine the consideration of repair/rehabilitation costs and travel cost to identify a repair/rehabilitation approach that maximizes benefit.

This paper describes a system architecture prototype for a web-based economic evaluation system that permits a user to access services anywhere via an internet-connected PC and helps decision makers enhance the effectiveness of repair/rehabilitation plans.

\section{REFERENCES}

[1] Rene B. Testa, Bridge maintenance level assessment, Computer-aided civil and infrastructure engineering $17 \quad$ (2002) 358-367.

[2] GA-based algorithm for selecting optimal repair and rehabilitation methods for reinforced concrete (RC) bridge decks, Cheol-Kyu Lee, Sung-Keun Kim, Automation in construction (2006)

[3] T.F. Fwa, W.T. Chan, C.Y. Tan, Genetic algorithms programming of road maintenance and rehabilitation, J. of Trans. Engrg., ASCE 122 (3) (1996) 246-253.

[4] H. Furuta, T. Ichida, M. Dogaki, A decision support system for maintenance of reinforced concrete decks of highway bridges, J. of Structural Engrg.(A), JSCE 44-2 (1998) 511-520.

[5] Ayaho Miyamoto, Kei Kawamura, Hideaki Nakamura, Bridge Management System and Maintenance Optimization for Existing Bridges, Computer-Aided Civil and Infrastructure Engineering 15 (2000) 45-55.

[6] W.V. Harper, Selection of ideal maintenance strategies in a network-level bridge management system, Transp. Res. Rec., vol. 1268, TRB, Washington, D.C., 1991, pp. 59-67.

[7] C. Liu, A. Hammad, Y. Itoh, Maintenance strategy optimization of bridge decks using genetic algorithm, J. of Trans. Engrg., ASCE 123 (2) (1997) 91-100.

[8] Wardrop, J. G., Some theoretical aspects of road traffic research, Proceedings, Institute of Civil Engineers, PART II, Vol.1, (1952) pp. $325-378$

[9] Ehlen, Mark A., Life-Cycle Costs of New Construction Materials, Journal of Infrastructure Systems, December 1997, pp. 129-133. 